\title{
Differences in Oral Health Status between Rural and Urban Populations of Korean Elders: A Population-Based Study from the Korean National Health and Nutrition Examination Survey VI (2013 2015)
}

\author{
Yong-Keum Choi ${ }^{1}$ and Eun-Jeong $\mathrm{Kim}^{2, \dagger}$ \\ ${ }^{1}$ Department of Dental Hygiene, College of Health Science and Genome-based BiolT Convergence Institute, Sun Moon \\ University, Asan 31460, \\ ${ }^{2}$ Dental Research Institution, School of Dentistry, Seoul National University, Seoul 03080, Korea
}

\begin{abstract}
Background: Edentulism is associated with socioeconomic status, rural residence, and chronic disease, but no studies have investigated edentulism and residence factors together. All information that drives a better understanding of the factors related to edentulism plays an important role in the planning and delivery of appropriate dental services for the elderly by national and oral health professionals. This study was designed to investigate the prevalence of edentulism in adults aged over 60 years in Korea and to examine whether there are differences in dentate status between people living in urban and rural areas after controlling for sociodemographic and other related factors.

Methods: The data for this study were collected from 2013 to 2015 as part of the Korea National Health and Nutrition Examination Survey VI, those individuals aged over 60 years and who had complete datasets were included $(5,071)$. The number of teeth and residence status were categorized into two groups: edentate and dentate (1 or more); urban and rural. Multiple multivariate logistic regression analyses were sequentially applied to assess the association between dentate status and residence status after adjusting for potential confounders.

Results: Rural areas, lower household income, and lower education levels were associated with a higher edentate rate. The number of teeth was lower in rural areas than in urban areas. After adjusting for various factors, statistically significant associations were present for women, low household income, low education level, poor perceived health status, and alcohol consumption in participants.

Conclusion: Elders living in rural areas had poorer oral health than elders living in urban areas. The government will need to provide effective systems for promoting oral health for elders living in rural areas.
\end{abstract}

Key Words: Aged, Oral health, Residence characteristics

\section{Introduction}

Edentulism is the loss of all of one's natural teeth. It is considered a poor health result for oral health as well as for systemic health and can significantly reduce the quality of life ${ }^{1-3)}$. Many researchers have pointed out that edentulism can have serious negative effects on mental and physical health. In addition, previous studies have reported that tooth loss among patients without teeth is associated with behavioral changes due to lake of self-esteem, disliked appearance, intimate relationships and close relationships and loss of behavior ${ }^{4)}$. Another study found that the greater the number of missing teeth, regardless of age, gender, or education, the more daily life met the reduced behavior ${ }^{55}$.

The proportion of edentulism is decreasing as health concerns and policies are increasing worldwide. In 1976, $66 \%$ of people over 65 years old were dentulous, and in 1995 , the prevalence had decreased to $42 \%^{6}$. In the US, edentulism among persons $45 \sim 54$ years of age decreased from $20 \%$ in $1960 \sim 1962$ to approximately $9 \%$ in $1988 \sim$ 
1994. In 1999 2002, the Centers for Disease Control and Prevention (CDC) reported that $8 \%$ of US adults 20 years of age and older were completely edentulous ${ }^{7,8)}$. However, a previous study on edentulism showed that the proportion of edentulous adults was reduced across the country, but in rural areas, the proportion of edentulous adults was higher and the rate of decline was slower than that of large cities $^{9)}$. The current oral disease patterns reflect the implementation of plans for improving life conditions, behavioral and environmental factors, oral health systems, and living conditions ${ }^{10)}$. The biggest burden of oral disease is poor people worldwide. People living in rural areas can face many shortcomings associated with edentulousness. Nonmetropolitan populations are expected to be disadvantaged because of their low level of overall education, high poverty rates, high morbidity and mortality rates, and fewer dentists and other oral health professionals ${ }^{11-13)}$. Not surprisingly, many of the rural dwellers have been found to be more condition than urban dwellers ${ }^{14)}$.

Analyzing the causes of loss of teeth by individual case is a complex and multifactorial process involving subjective factors and less important factors, such as cultural factors, sociocultural status, diagnoses, and ethnicity, as well as many objective data, such as tooth decay, periodontal disease, and trauma ${ }^{15)}$. Edentulism is associated with socioeconomic status, rural residence, and chronic disease, but no studies have investigated these factors with edentulism together. All information that leads to better understanding of the factors associated with edentulism plays an important role in the planning and delivery of appropriate dental services for the rural area dwellers by national and oral health professionals ${ }^{16)}$.

Thus, this study was designed to investigate the prevalence of edentulism in adults aged over 60 years in Korea and to examine whether there are differences in dentate status between people living in urban and rural areas after controlling for sociodemographic and other related factors.

\section{Materials and Methods}

\section{Sampling procedures}

The data for this study were collected from 2013 to 2015 as part of the Korea National Health and Nutrition
Examination Survey (KNHANES), which is periodically carried out by the Korean Centers for Disease Control and Prevention (KCDC). The sampling protocol included a complex, stratified, multistage, probability-based design with proportional allocation, as well as a cluster survey of a representative sample of the noninstitutionalized civilian population in Korea. The Korean Ministry of Health and Welfare performed the survey. The target population of the survey included all noninstitutionalized civilian Korean individuals aged 1 year or older. The 2005 National Census Registry randomly selected the participants from various geographic areas, ages, and gender groups.

The survey consisted of questions about overall health (household survey, health interview survey, and health behavior survey), a nutrition survey (dietary behavior, dietary supplements, nutrition knowledge, food intake, and food stability), and oral and health examinations (physical measurement, blood and urine tests, blood pressure and pulse measurements, pulmonary function tests, visual acuity and refraction tests, color vision tests, and hearing tests). Face-to-face interviews were performed using a structured questionnaire by trained interviewers. The health interviews and health examinations were conducted by trained medical professionals and interviewers, and the oral examinations were performed by dentists and medical professionals. Before participating in the study, all participants signed an informed consent form.

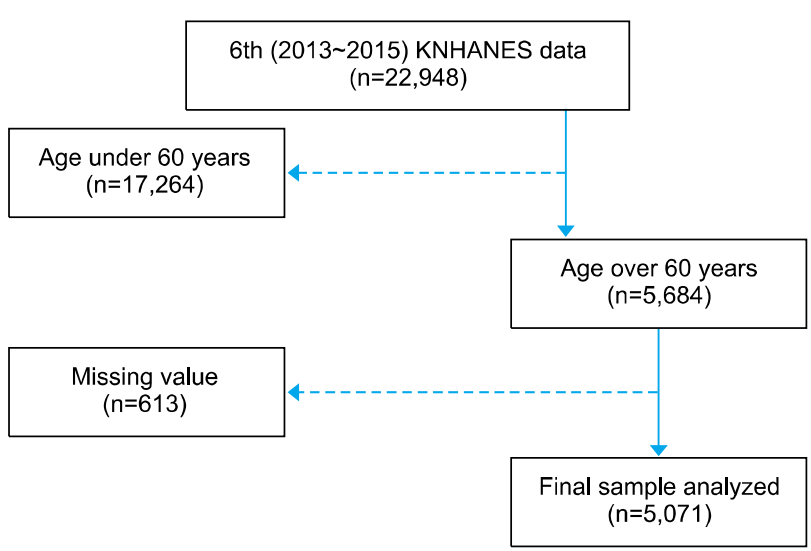

Fig. 1. Overview of the study samples. KNHANES: the Korea National Health and Nutrition Examination Survey. 


\section{Eligibility and exclusion criteria}

Out of the 22,948 subjects who participated in the KNHANES, only those individuals aged over 60 years and who had complete datasets were included in this analysis. The final sample included 5,071 participants (2,194 men and 2,877 women). Detailed descriptions of the sampling methods and survey contents are described in previous studies (Fig. 1) ${ }^{17-19)}$.

\section{Assessment of the number of teeth and categorization of edentate and dentate}

Trained dentists conducted the oral examinations of the participants and recorded their oral health status. Missing teeth, impacted teeth or implants, and third molars were excluded when counting the number of teet ${ }^{20}$. The number of teeth was categorized into two groups: edentate (0) and dentate (1 or more).

\section{Classification of residence}

The residence status was categorized into two groups: urban and rural. An area was classified as 'urban' if the population was over 50,000 in the administrative district, and an area was classified as 'rural' if the population was less than 50,000 in the administrative district.

\section{Assessment of potential confounders}

Information on sociodemographic factors, oral health status and behaviors, and general health status and behaviors was collected from the participants' responses to a standardized questionnaire through personal interviews. Participants were categorized into three age groups: $60 \sim 69$, $70 \sim 79$, and 80 years and over. Household income was the family income adjusted for the number of family members. It was categorized into quartiles: less than $25 \%, 25 \sim 50 \%$, $50 \sim 75 \%$ and over $75 \%$. The highest diploma earned was used to assess a participant's education level.

The general health behaviors and status information included hypertension, diabetes mellitus, perceived health status, smoking status, and alcohol consumption. Hypertension was defined as an average systolic blood pressure over 140 $\mathrm{mmHg}$ or diastolic blood pressure over $90 \mathrm{mmHg}$. Diabetes mellitus was defined as a fasting glucose level over $126 \mathrm{mg} / \mathrm{dl}$. Participants were categorized as normal (body mass index [BMI], 18.5 to $<25 \mathrm{~kg} / \mathrm{m}^{2}$ ), underweight (BMI $<18.5 \mathrm{~kg} / \mathrm{m}^{2}$ ), or obese (BMI $\geq 25.0$ $\left.\mathrm{kg} / \mathrm{m}^{2}\right)^{21}$. The self-reported perceived health status was divided into three categories: good, ordinary, and poor. Regarding smoking status and alcohol consumption, the subjects were divided into two groups: yes and no.

\section{Statistical analysis}

The integrated weights were calculated and applied when integrating data for each year from 2013 to 2015. All analytical procedures were performed in accordance with the Guidelines for the Use of KNHANES ${ }^{22}$.

In the analysis, the outcome variable was dentate status, and the main explanatory variable was residence status. Statistically significant differences in the characteristics of participants' dentate status were examined using frequency chi-square tests. All data are presented as weighted percentages and standard errors.

Multiple multivariate logistic regression analyses were sequentially applied to assess the association between dentate status and residence status after adjusting for potential confounders. A multivariate logistic regression was used to compute unadjusted and adjusted odds ratios (AORs) and confidence intervals (CIs). The AORs, CIs, and trend $\mathrm{p}$-values for multicategory variables were used. Subgroup analyses by age and gender were also performed to identify risk groups. All statistical analyses were performed using IBM SPSS Statistics for Windows/ Macintosh, ver. 21.0 (IBM Corp., Armonk, NY, USA). Statistical significance was set at a value of $\mathrm{p}<0.05$.

\section{Results}

Of the 5,071 participants, the prevalence of edentulism was estimated to be $14.9 \%$. Tables 1 and 2 show the characteristics of the study participants according to the results of dentate status and residence status. As participants get older, the proportion of edentulism increases. Rural areas, lower household income, and lower education levels were associated with a higher edentate rate (rural residence: $34.5 \%$, household income $<25 \%: 56.0 \%$, and primary school education level: $71.1 \%$; data was now shown). The edentate rate was high when the perceived health status 
Table 1. Characteristics of the Participants according to Dentate Status $(n=5,071)$

\begin{tabular}{|c|c|c|c|c|c|c|}
\hline \multirow{2}{*}{ Variable } & \multirow{2}{*}{ Total } & \multicolumn{2}{|c|}{ Edentate $(n=340)$} & \multicolumn{2}{|c|}{ Dentate $(n=4,731)$} & \multirow{2}{*}{$\mathrm{p}$-value } \\
\hline & & $\mathrm{n}$ & $\%(95 \% \mathrm{CI})^{\mathrm{a}}$ & $\mathrm{n}$ & $\%(95 \% \mathrm{CI})^{\mathrm{a}}$ & \\
\hline Age (y) & & & & & & $<0.001$ \\
\hline $60 \sim 69$ & 2,642 & 76 & $2.7(2.1 \sim 3.5)$ & 2,566 & $97.3(96.5 \sim 97.9)$ & \\
\hline $70 \sim 79$ & 1,960 & 167 & $8.9(7.4 \sim 10.6)$ & 1,793 & $91.1(89.4 \sim 92.6)$ & \\
\hline 80 and over & 469 & 97 & $18.8(15.3 \sim 22.9)$ & 372 & $81.2(77.1 \sim 84.7)$ & \\
\hline Gender & & & & & & 0.132 \\
\hline Men & 2,194 & 170 & $7.2(6.1 \sim 8.5)$ & 2,024 & $92.8(91.5 \sim 93.9)$ & \\
\hline Women & 2,877 & 170 & $6.0(5.0 \sim 7.1)$ & 2,707 & $94.0(92.9 \sim 95.0)$ & \\
\hline Residence & & & & & & $<0.001$ \\
\hline Urban & 3,774 & 206 & $5.6(4.8 \sim 6.6)$ & 3,568 & $94.4(93.4 \sim 95.2)$ & \\
\hline Rural & 1,297 & 134 & $9.3(7.6 \sim 11.2)$ & 1,163 & $90.7(88.8 \sim 92.4)$ & \\
\hline Household income $(\%)^{\mathrm{c}}$ & & & & & & $<0.001$ \\
\hline$<25$ & 2,049 & 199 & $9.2(7.8 \sim 11.0)$ & 1,850 & $90.8(89.0 \sim 92.2)$ & \\
\hline $25 \sim 50$ & 1,415 & 76 & $5.5(4.3 \sim 7.0)$ & 1,339 & $94.5(93.0 \sim 95.7)$ & \\
\hline $50 \sim 75$ & 919 & 44 & $4.8(3.4 \sim 6.7)$ & 875 & $95.2(93.3 \sim 96.6)$ & \\
\hline$>75$ & 688 & 21 & $3.2(2.0 \sim 4.9)$ & 667 & $96.8(95.1 \sim 98.0)$ & \\
\hline Education level & & & & & & $<0.001$ \\
\hline Primary school & 2,874 & 242 & $8.2(7.0 \sim 9.5)$ & 2,632 & $91.8(90.5 \sim 93.0)$ & \\
\hline Middle school & 748 & 31 & $4.8(3.2 \sim 7.0)$ & 717 & $95.2(93.0 \sim 96.8)$ & \\
\hline High school & 945 & 51 & $4.9(3.5 \sim 6.6)$ & 894 & $95.1(93.4 \sim 96.5)$ & \\
\hline University or college & 504 & 16 & $2.7(1.6 \sim 4.6)$ & 488 & $97.3(95.4 \sim 98.4)$ & \\
\hline Perceived health status & & & & & & 0.003 \\
\hline Good & 1,153 & 67 & $5.1(3.9 \sim 6.6)$ & 1,086 & $94.9(93.4 \sim 96.1)$ & \\
\hline Ordinary & 2,422 & 150 & $6.0(4.9 \sim 7.2)$ & 2,272 & $94.0(92.8 \sim 95.1)$ & \\
\hline Poor & 1,496 & 123 & $8.5(7.0 \sim 10.4)$ & 1,373 & $91.5(89.6 \sim 93.0)$ & \\
\hline Smoking & & & & & & $<0.001$ \\
\hline No & 3,094 & 160 & $5.2(4.3 \sim 6.3)$ & 2,934 & $94.8(93.7 \sim 95.7)$ & \\
\hline Yes & 1,977 & 180 & $8.5(7.2 \sim 9.9)$ & 1,797 & $91.5(90.1 \sim 92.8)$ & \\
\hline Alcohol consumption & & & & & & 0.001 \\
\hline No & 1,216 & 105 & $8.9(7.1 \sim 11.1)$ & 1,111 & $91.1(88.9 \sim 92.9)$ & \\
\hline Yes & 3,855 & 235 & $5.8(5.0 \sim 6.6)$ & 3,620 & $94.2(93.4 \sim 95.0)$ & \\
\hline Hypertension & & & & & & 0.805 \\
\hline No & 2,519 & 168 & $6.4(5.4 \sim 7.6)$ & 2,351 & $93.6(92.4 \sim 94.6)$ & \\
\hline Yes & 2,552 & 172 & $6.6(5.6 \sim 7.8)$ & 2,380 & $93.4(92.2 \sim 94.4)$ & \\
\hline Diabetes mellitus & & & & & & 0.299 \\
\hline No & 4,056 & 262 & $6.3(5.5 \sim 7.3)$ & 3,794 & $93.7(92.7 \sim 94.5)$ & \\
\hline Yes & 1,015 & 78 & $7.3(5.7 \sim 9.4)$ & 937 & $92.7(90.6 \sim 94.3)$ & \\
\hline
\end{tabular}

${ }^{a}$ Weighted percent, $95 \%$ confidence interval (CI). ${ }^{b}$ p-value obtained from chi-square test. ${ }^{c}$ Monthly average household income $(\sqrt{ }:$ the number of household members).

was poor (8.5\%) and when participants smoked $(8.5 \%$; $\mathrm{p}<0.05$ ). Table 2 shows the number of teeth according to the residence area. Overall, the number of teeth was lower in rural areas than in urban areas. The lower the income level, the lower the education level, and as age increased, the number of teeth was lower in rural areas than in urban areas. When the subjective health status was poor and when the participants smoked and consumed alcohol, the number of teeth was lower in rural areas than in urban areas.

Compared with urban areas, the odds ratios for becoming edentulous when living in rural areas are shown in Table 3. Based on the results in Table 3, after adjusting for sociodemographic factors and general health and behavior status factors, statistically significant associations were present for women $(\mathrm{AOR}=2.1,95 \% \mathrm{CI}=1.42 \sim 3.09)$, low 
Yong-Keum Choi and Eun-Jeong Kim : Differences in Oral Health Status between Rural and Urban Elders

Table 2. Number of Teeth Present in a Population Aged 60 Years and Older according to Residence, by Variable ( $n=5,071$ )

\begin{tabular}{|c|c|c|c|c|c|}
\hline \multirow{2}{*}{ Variable } & \multicolumn{2}{|c|}{ Urban $(n=3,774)$} & \multicolumn{2}{|c|}{ Rural $(n=1,297)$} & \multirow{2}{*}{ p-value } \\
\hline & Mean teeth present & $(95 \% \mathrm{CI})$ & Mean teeth present & $(95 \% \mathrm{CI})$ & \\
\hline \multicolumn{6}{|l|}{ Age (y) } \\
\hline $60 \sim 69$ & 20.54 & $20.00 \sim 21.08$ & 20.11 & $19.25 \sim 20.97$ & 0.08 \\
\hline $70 \sim 79$ & $17.07^{\mathrm{a}}$ & $16.39 \sim 17.76$ & 14.85 & $13.83 \sim 15.87$ & $<0.001$ \\
\hline 80 and over & $13.06^{\mathrm{a}}$ & $11.80 \sim 14.31$ & 10.28 & $8.49 \sim 12.06$ & 0.301 \\
\hline \multicolumn{6}{|l|}{ Gender } \\
\hline Men & 16.97 & $16.18 \sim 17.76$ & 16.05 & $14.99 \sim 17.09$ & 0.025 \\
\hline Women & 16.81 & $16.04 \sim 17.57$ & 14.12 & $12.91 \sim 15.32$ & $<0.001$ \\
\hline \multicolumn{6}{|l|}{ Household income $(\%)^{\mathrm{b}}$} \\
\hline$<25$ & $15.86^{\mathrm{a}}$ & $15.11 \sim 16.62$ & 14.69 & $13.54 \sim 15.85$ & 0.12 \\
\hline $25 \sim 50$ & $16.76^{\mathrm{a}}$ & $15.95 \sim 17.57$ & 14.58 & $13.20 \sim 15.95$ & 0.14 \\
\hline $50 \sim 75$ & $16.88^{\mathrm{a}}$ & $16.04 \sim 17.73$ & 15.65 & $14.33 \sim 16.97$ & 0.24 \\
\hline$>75$ & 18.04 & $17.23 \sim 18.86$ & 15.38 & $13.37 \sim 17.40$ & 0.01 \\
\hline \multicolumn{6}{|l|}{ Education level } \\
\hline Primary school & 15.80 & $15.10 \sim 16.50$ & 13.45 & $12.41 \sim 14.49$ & $<0.001$ \\
\hline Middle school & 16.23 & $15.30 \sim 17.16$ & 15.11 & $13.59 \sim 16.64$ & 0.29 \\
\hline High school & 16.94 & $16.14 \sim 17.74$ & 15.40 & $13.75 \sim 17.06$ & 0.39 \\
\hline University or college & 18.58 & $17.70 \sim 19.47$ & 16.34 & $14.64 \sim 18.04$ & 0.45 \\
\hline \multicolumn{6}{|l|}{ Perceived health status } \\
\hline Good & 17.32 & $16.54 \sim 18.10$ & 15.17 & $13.99 \sim 16.35$ & 0.03 \\
\hline Ordinary & 16.78 & $16.09 \sim 17.47$ & 15.25 & $14.11 \sim 16.40$ & $<0.001$ \\
\hline Poor & 16.56 & $15.77 \sim 17.36$ & 14.81 & $13.55 \sim 16.06$ & 0.08 \\
\hline \multicolumn{6}{|l|}{ Smoking } \\
\hline No & 18.18 & $17.45 \sim 18.92$ & 16.82 & $15.80 \sim 17.85$ & 0.08 \\
\hline Yes & $15.59^{\mathrm{a}}$ & $14.82 \sim 16.37$ & 13.33 & $12.06 \sim 14.60$ & $<0.001$ \\
\hline \multicolumn{6}{|l|}{ Alcohol consumption } \\
\hline No & 17.24 & $16.69 \sim 17.78$ & 15.65 & $14.69 \sim 16.62$ & $<0.001$ \\
\hline Yes & 16.54 & $15.69 \sim 17.39$ & 14.50 & $13.29 \sim 15.71$ & 0.06 \\
\hline \multicolumn{6}{|l|}{ Hypertension } \\
\hline No & 16.54 & $15.84 \sim 17.25$ & 14.54 & $13.42 \sim 15.65$ & 0.12 \\
\hline Yes & $17.23^{\mathrm{a}}$ & $16.60 \sim 17.87$ & 15.62 & $14.59 \sim 16.64$ & $<0.001$ \\
\hline \multicolumn{6}{|l|}{ Diabetes mellitus } \\
\hline No & 17.43 & $16.83 \sim 18.02$ & 15.46 & $14.56 \sim 16.34$ & 0.47 \\
\hline Yes & $16.35^{\mathrm{a}}$ & $15.54 \sim 17.16$ & 14.70 & $13.30 \sim 16.10$ & $<0.001$ \\
\hline
\end{tabular}

Mean number of existing teeth, $95 \%$ confidence interval (CI), and p-value obtained from chi-square test.

The data were analyzed by the complex samples general linear model.

${ }^{a}$ Statistical significance test with, age: $60 \sim 69$, gender: men, household income: $>75 \%$, education level: university, smoking, alcohol, hypertension, diabetes mellitus: no, perceived health status: good, at $p<0.05$. ${ }^{\mathrm{b}}$ Monthly average household income $(\sqrt{ }:$ the number of household members).

household income $(\mathrm{AOR}=1.5,95 \% \mathrm{CI}=1.02 \sim 2.20$ for $<25 \%, \mathrm{AOR}=1.71,95 \% \mathrm{CI}=1.01 \sim 2.89$ for $25 \sim 50 \%)$, low education level $(\mathrm{AOR}=1.81,95 \% \mathrm{CI}=1.30 \sim 2.52$ for primary school), poor perceived health status $(\mathrm{AOR}=1.78$, $95 \% \mathrm{CI}=1.56 \sim 2.73$ for ordinary, $\mathrm{AOR}=1.58,95 \% \mathrm{CI}=$ $1.01 \sim 2.46$ for poor), and alcohol consumption $(\mathrm{AOR}=$ $1.72,95 \% \mathrm{CI}=0.27 \sim 2.33$ ) in participants.

\section{Discussion}

Health inequalities mean differences, diversity and disparities in health outcomes between individuals and groups ${ }^{10)}$. This health imbalance is an inevitable and unfair demographic health difference in terms of social justice, ethics and human rights ${ }^{23)}$. While oral health has improved significantly over the past few decades, the social gradient 
Table 3. Sociodemographic Characteristic Associated with Edentulism and Residence Status (Reference=Urban Area)

\begin{tabular}{|c|c|c|c|}
\hline \multirow[t]{2}{*}{ Variable } & $\begin{array}{c}\text { Adjusted } \\
\text { odds ratio }\end{array}$ & \multirow{2}{*}{$\begin{array}{c}95 \% \\
\text { confidence } \\
\text { interval }\end{array}$} & \multirow[t]{2}{*}{ p-value } \\
\hline & Rural & & \\
\hline \multicolumn{4}{|l|}{ Age (y) } \\
\hline $60 \sim 69$ & 1.17 & $0.69 \sim 1.97$ & 0.562 \\
\hline $70 \sim 79$ & 1.76 & $1.19 \sim 2.60$ & 0.004 \\
\hline 80 and over & 1.35 & $0.80 \sim 2.28$ & 0.256 \\
\hline \multicolumn{4}{|l|}{ Gender } \\
\hline Men & 1.37 & $0.95 \sim 1.96$ & 0.091 \\
\hline Women & 2.10 & $1.42 \sim 3.09$ & $<0.001$ \\
\hline \multicolumn{4}{|l|}{ Household income $(\%)$} \\
\hline$<25$ & 1.50 & $1.02 \sim 2.20$ & 0.038 \\
\hline $25 \sim 50$ & 1.71 & $1.01 \sim 2.89$ & 0.047 \\
\hline $50 \sim 75$ & 1.04 & $0.48 \sim 2.27$ & 0.914 \\
\hline$>75$ & 2.66 & $0.95 \sim 7.42$ & 0.062 \\
\hline \multicolumn{4}{|l|}{ Education level } \\
\hline Primary school & 1.81 & $1.30 \sim 2.52$ & 0.001 \\
\hline Middle school & 0.52 & $0.20 \sim 1.33$ & 0.172 \\
\hline High school & 1.22 & $0.57 \sim 2.61$ & 0.822 \\
\hline$\geq$ University or college & 1.44 & $0.23 \sim 6.92$ & 0.701 \\
\hline \multicolumn{4}{|l|}{ Perceived health status } \\
\hline Good & 1.69 & $0.95 \sim 3.00$ & 0.072 \\
\hline Ordinary & 1.78 & $1.56 \sim 2.73$ & 0.009 \\
\hline Poor & 1.58 & $1.01 \sim 2.46$ & 0.043 \\
\hline \multicolumn{4}{|l|}{ Smoking } \\
\hline No & 2.12 & $1.24 \sim 3.18$ & $<0.001$ \\
\hline Yes & 1.40 & $0.97 \sim 2.01$ & 0.071 \\
\hline \multicolumn{4}{|l|}{ Alcohol consumption } \\
\hline No & 1.64 & $0.99 \sim 2.70$ & 0.051 \\
\hline Yes & 1.72 & $0.27 \sim 2.33$ & 0.001 \\
\hline \multicolumn{4}{|l|}{ Hypertension } \\
\hline No & 1.64 & $1.15 \sim 2.33$ & 0.006 \\
\hline Yes & 1.79 & $1.21 \sim 2.66$ & 0.004 \\
\hline \multicolumn{4}{|l|}{ Diabetes mellitus } \\
\hline No & 1.33 & $0.71 \sim 2.61$ & 0.345 \\
\hline Yes & 1.87 & $1.35 \sim 2.50$ & $<0.001$ \\
\hline
\end{tabular}

Models were adjusted for age, gender, household income, education, perceived health status, smoking, alcohol consumption, hypertension, and diabetes mellitus except the stratum.

Determined by multivariate logistic regression.

of oral health stands out in the prevention and treatment of disease, and inequality still remains ${ }^{24)}$. The greatest burden of oral disease worldwide appears in disadvantaged and poor populations ${ }^{25}$. There are significant differences in oral health service distribution, utilization and outcomes between developing and developed countries and urban and rural areas ${ }^{26,27}$. Thus, the results of this study show clear and distinct social gradient in clinical and subjective oral health indicators based on residence status after adjusting for age, gender, household income, education level, smoking status, alcohol consumption, hypertension, and diabetes mellitus. There are no reports on oral health behavior and the lack of social epidemiological data on oral disease in urban and rural areas. To the best of our knowledge, this study provides the first evidence to compare oral health status among urban and rural dwellers from a Korean population using a nationally representative data sample.

The reported prevalence of edentulism currently varies from country to country, ranging from $6 \%$ to $78 \%$ of the population ${ }^{28)}$. According to the results of this study, $14.9 \%$ of elders over 60 years of age were edentate, which is a lower figure than that of a Spanish population survey $(20.7 \%)^{16)}$ but higher than that of Chinese national data $(8.64 \%)^{29)}$. Many studies have identified a strong association between demographic and socioeconomic factors and edentulism ${ }^{30-32)}$. The study also found age, residence area, education and economic level to be related to edentulism. The association between aging and increased tooth loss has been clearly demonstrated by previous studies. Our results agreed with this finding: as age increased, the proportion of edentate participants decreased significantly. As with other studies ${ }^{31,33)}$, high economic status and education level are inversely related to the likelihood of tooth loss. In this study, the proportion of edentulous people was higher when the residence area was rural, the economic level was low, and the education level was low. This can be explained by the lack of oral health knowledge and behavior as well as lack of access of these groups to dentistry. There was an important association between residence status and oral status, which may be partly due to the relative difficulty of rural residents in accessing dental care. Many systemic diseases have been reported to be associated with tooth loss ${ }^{34-36}$; our study showed similar results as previous studies. Several previous studies have shown that smokers lose more teeth than nonsmokers due to the adverse effects of tobacco on oral health and dental caries $^{32,33)}$. Our study also showed results consistent with previous studies. There was a significant increase in edentulous elders in the group that smoked compared to the group that did not smoke. 
After adjusting for well-known potential confounders in the fully adjusted model, it showed a dose effect trend. In rural areas, when the prevalence odds ratio of edentulism is analyzed by socioeconomic status by adjusting all variables compared with urban areas, the odds ratios are more than twice as high for women. When the household income and education levels are low and when participants smoke and consume alcohol, a high prevalence odds ratio of edentulism is seen. These our knowledge, no other study results have been reported results similar to our results, so it is difficult to compare to this study. However, this edentulism prevalence odds ratio seems to be high because the elders in rural areas are vulnerable to various socioeconomic conditions.

Tooth loss is thought to be an early marker of decline and weakness ${ }^{37)}$. Edentulism is independently associated with the onset of physical disability ${ }^{38)}$. Complete tooth loss is associated with slower walking speeds and physical and cognitive decline in a previous study ${ }^{37)}$. As a result, functional decline can cause difficulties in performing oral hygiene practices and using dental services; thus, the elderly may be at risk of dental disease and tooth loss. In addition, a decline in masticatory function due to a large amount of tooth loss can lead to poor nutrition, which can lead to systemic diseases such as diabetes, cardiovascular diseases and dementia ${ }^{39)}$. It is extremely important to encourage preventive oral health services for elderly living in rural areas where health services are not available. Implementing appropriate dental services and national programs for these older people will help reduce edentulism. This is especially important in rural and remote areas to which dental professionals have limited access.

Some limitations should be considered when interpreting our findings. First, due to the restriction of the crosssectional design, the causality of the association between oral health status and dwelling status is unclear. Second, among the survey methods used in this study, the questionnaire method was used, and the risk of recall bias could have occurred because the participants could have experienced memory errors.

Nevertheless, this study has several strengths. A largescale nationally representative sample of the Korean population was used in this study. Moreover, the quality evaluation of all steps (data collection, data processing, survey administration, and laboratory analysis) of this sample was performed by the $\mathrm{KCDC}^{22)}$. In addition, a trained dentist assessed periodontal and oral health status, and a professional examiner conducted and documented all general health screenings. In addition, it was uncertain whether socioeconomic status would affect oral health status. To overcome this limitation, we analyzed various adjustments in the logistic regression model. The current study results provide evidence for an association between residential area and socioeconomic status and oral health status in Korean elders.

This study was conducted to provide information on the oral health of urban and rural populations, and the results will help plan and evaluate the national oral health program. Elders living in rural areas had poorer oral health than elders living in urban areas. As a result, the government will need to provide effective systems for promoting oral health for elders living in rural areas. It will also be important to include oral care items in the various existing health services of each country. Of course, new precautionary policies for elders in rural areas are also important, but it government include oral care in existing health services, it will get good results. In addition, rural areas, where dental visit are not easy to visit, will need to visit health centers to promote health center-linked programs and make efforts for more effective oral care by expanding on-site oral health care programs.

\section{Notes}

\section{Conflict of interest}

No potential conflict of interest relevant to this article was reported.

\section{Ethical approval}

The sixth KNHANES was a cross-sectional survey conducted by the Korea Center for Disease Control and Prevention (KCDCP) from 2012 to 2015 . The KNHANES was approved by the KCDC Institutional Review Board (2013-07CON-03-4C, 2013-12EXP-03-5C, and 2015-0102-6C). 


\section{ORCID}

Yong-Keum Choi, https://orcid.org/0000-0002-5537-4208

Eun-Jeong Kim, https://orcid.org/0000-0002-6316-7807

\section{Acknowledgements}

We acknowledge the Korea Centers for Disease Control and Prevention (KCDCP) which provided data of the sixth Korea National Health and Nutrition Examination Survey (KNHANES IV) from 2012-2015 to be used in this study.

\section{References}

1. Jones JA, Adelson R, Niessen LC, Gilbert GH: Issues in financing dental care for the elderly. J Public Health Dent 50: 268-275, 1990. https://doi.org/10.1111/j.1752-7325.1990.tb02134.x

2. Kim HN, Kim KR, Kim JB: The association between number of present teeth and oral function in Korean adults aged 55 84 years. J Dent Hyg Sci 15: 340-347, 2015. https://doi.org/10.17135/jdhs.2015.15.3.340

3. Slade GD, Spencer AJ: Social impact of oral conditions among older adults. Aust Dent J 39: 358-364, 1994. https://doi.org/10.1111/j.1834-7819.1994.tb03106.x

4. Davis DM, Fiske J, Scott B, Radford DR: The emotional effects of tooth loss: a preliminary quantitative study. Br Dent J 188: 503-506, 2000. https://doi.org/10.1038/sj.bdj.4800522

5. Al-Omiri MK, Karasneh JA, Lynch E, Lamey PJ, Clifford TJ: Impacts of missing upper anterior teeth on daily living. Int Dent J 59: 127-132, 2009. https://doi.org/10.1922/IDJ_1994ALOmiri06

6. Carter KD: National dental telephone interview survey 1995. AIHW Dental Statistics and Research Unit, the University of Adelaide, Adelaide, 1995.

7. Beltrán-Aguilar ED, Barker LK, Canto MT, et al.: Surveillance for dental caries, dental sealants, tooth retention, edentulism, and enamel fluorosis - United States, 1988-1994 and 1999-2002. Morbidity and Mortality Weekly Report: Surveillance Summaries, pp.1-43, 2005.

8. Centers for Disease Control and Prevention (CDC): Ten great public health achievements--United States, 1900-1999. Morbidity and Mortality Weekly Report, pp.241-243, 1999.

9. Osterberg T, Carlsson GE, Sundh W, Fyhrlund A: Prognosis of and factors associated with dental status in the adult
Swedish population, 1975-1989. Community Dent Oral Epidemiol 23: 232-236, 1995.

https://doi.org/10.1111/j.1600-0528.1995.tb00237.x

10. Pitts N, Amaechi B, Niederman R, et al.: Global oral health inequalities: dental caries task group--research agenda. Adv Dent Res 23: 211-220, 2011. https://doi.org/10.1177/0022034511402016

11. Hugo G: Australia's changing non-metropolitan population. In: Wilkinson D, Blue I, eds. The new rural health. Oxford University Press, Melbourne, pp.12-43, 2002.

12. Strong K. Trickett P, Titulaer I, Bhatia K: Health and family services in rural and remote Australia. Department of Health and Family Services, Canberra, 1998.

13. Steele L, Pacza T, Tennant M: Rural and remote oral health, problems and models for improvement: a Western Australian perspective. Aust J Rural Health 8: 22-28, 2000. https://doi.org/10.1046/j.1440-1584.2000.81224.x

14. Vargas CM, Dye BA, Hayes KL: Oral health status of rural adults in the United States. J Am Dent Assoc 133: 1672-1681, 2002. https://doi.org/10.14219/jada.archive.2002.0120

15. Yoon YS, Kwon YO: The present state and prospect of geriatric denture prosthetic dentistry affairs among community dental hygienists. J Dent Hyg Sci 6: 255-261, 2006.

16. Eustaquio-Raga MV, Montiel-Company JM, Almerich-Silla JM: Factors associated with edentulousness in an elderly population in Valencia (Spain). Gac Sanit 27: 123-127, 2013. https://doi.org/10.1016/j.gaceta.2012.02.009

17. Lee JB, Yi HY, Bae KH: The association between periodontitis and dyslipidemia based on the Fourth Korea National Health and Nutrition Examination Survey. J Clin Periodontol 40: 437-442, 2013. https://doi.org/10.1111/jcpe.12095

18. Kim DW, Park JC, Rim TT, et al.: Socioeconomic disparities of periodontitis in Koreans based on the KNHANES IV. Oral Dis 20: 551-559, 2014. https://doi.org/10.1111/odi.12168

19. Korea Centers for Disease Control and Prevention: 2009 Korea National Health and Nutrition Examination Survey: the 4th survey. Korea Centers for Disease Control and Prevention, Seoul, 2010.

20. Shin HS: The number of teeth is inversely associated with metabolic syndrome: a korean nationwide population-based study. J Periodontol 88: 830-838, 2017. https://doi/org/10.1902/jop.2017.170089 
21. World Health Organization. Regional Office for the Western Pacific. The Asia-Pacific perspective: redefining obesity and its treatment. Health Communications Australia, Sydney, 2000.

22. Kweon S, Kim Y, Jang MJ, et al.: Data resource profile: the Korea National Health and Nutrition Examination Survey (KNHANES). Int J Epidemiol 43: 69-77, 2014. https://doi.org/10.1093/ije/dyt228

23. Lee JY, Divaris K: The ethical imperative of addressing oral health disparities: a unifying framework. J Dent Res 93: 224-230, 2014. https://doi.org/10.1177/0022034513511821

24. Sgan-Cohen HD, Evans RW, Whelton H, Villena RS, MacDougall M, Williams DM: IADR Global Oral Health Inequalities Research Agenda (IADR-GOHIRA ${ }^{\mathbb{R}}$ ): a call to action. J Dent Res 92: 209-211, 2013. https://doi.org/10.1177/0022034512475214

25. Pitts N, Amaechi B, Niederman R, et al.: Global oral health inequalities: dental caries task group--research agenda. Adv Dent Res 23: 211-220, 2011. https://doi.org/10.1177/0022034511402016

26. Beaglehole R, Benzian H, Crail J, Mackay J: The oral health atlas: mapping a neglected global health issue. FDI World Dental Federation, Geneva, pp.96-103, 2009.

27. Bayne A, Knudson A, Garg A, Kassahun M: Promising practices to improve access to oral health care in rural communities. Retrieved February 6, 2015, from: http://www. norc.org/PDFs/Walsh\%20Center/Oral_Rural\%20Evaluation $\%$ 20Issue\%20Brief-6pg_mm.pdf(2013, February).

28. Petersen PE: The World Oral Health Report 2003: continuous improvement of oral health in the 21st century--the approach of the WHO Global Oral Health Programme. Community Dent Oral Epidemiol 2003:31 Suppl 1:3-23.

29. Ren C, McGrath C, Yang Y: Edentulism and associated factors among community-dwelling middle-aged and elderly adults in China. Gerodontology 34: 195-207, 2017. https://doi.org/10.1111/ger.12249

30. Kassebaum NJ, Bernabé E, Dahiya M, Bhandari B, Murray CJ, Marcenes W: Global burden of severe tooth loss: a systematic review and meta-analysis. J Dent Res 93(7 Suppl): 20S-28S, 2014. https://doi.org/10.1177/0022034514537828
31. Adams C, Slack-Smith LM, Larson A, O'Grady MJ: Edentulism and associated factors in people 60 years and over from urban, rural and remote Western Australia. Aust Dent J 48: 10-14, 2003. https://doi.org/10.1111/j.1834-7819.2003.tb00002.x

32. Medina-Solís CE, Pérez-Núñez R, Maupomé G, CasanovaRosado JF: Edentulism among Mexican adults aged 35 years and older and associated factors. Am J Public Health 96: 1578-1581, 2006. https://doi.org/10.2105/AJPH.2005.071209

33. Lin HC, Corbet EF, Lo ECM, Zhang HG: Tooth loss, occluding pairs, and prosthetic status of Chinese adults. J Dent Res 80: 1491-1495, 2001. https://doi.org/10.1177/00220345010800052101

34. Felton DA: Complete Edentulism and comorbid diseases: an update. J Prosthodont 25: 5-20, 2016. https://doi.org/10.1111/jopr.12350

35. Tôrres LH, da Silva DD, Neri AL, Hilgert JB, Hugo FN, Sousa ML: Association between underweight and overweight/ obesity with oral health among independently living Brazilian elderly. Nutrition 29: 152-157, 2013. https://doi.org/10.1016/j.nut.2012.05.011

36. Kong YM, Han GS: Relationships between obesity types and periodontitis according to characteristics of subjects. J Dent Hyg Sci 12: 279-286, 2012.

37. Tsakos G, Watt RG, Rouxel PL, de Oliveira C, Demakakos P: Tooth loss associated with physical and cognitive decline in older adults. J Am Geriatr Soc 63: 91-99, 2015. https://doi.org/10.1111/jgs.13190

38. Holm-Pedersen P, Schultz-Larsen K, Christiansen N, Avlund $\mathrm{K}$ : Tooth loss and subsequent disability and mortality in old age. J Am Geriatr Soc 56: 429-435, 2008. https://doi.org/10.1111/j.1532-5415.2007.01602.x

39. Kim EJ, Jin BH: Comparison of oral health status and daily nutrient intake between elders who live alone and elders who live with family: based on the Korean National Health and Nutrition Examination Survey (KNHANES VI) (2013-2015). Gerodontology 35: 129-138, 2018. https://doi.org/10.1111/ger.12334 